\title{
DÉFICIT NOMINAL ZERO
}

\section{Antonio Delfim Netto*}

Já lá se vão quase cinco anos desde que a Goldman-Sachs escolheu quatro países que na opinião de seus analistas tinham potencialidade para tornarem-se importantes players na economia mundial do século XXI. Construiu o acrônimo BRIC para designar essas “economias da esperança”: Brasil, Rússia, Índia e China. É claro que a situação inicial de cada um deles em matéria de Geografia e História tinha peculiaridades que condicionariam o seu desenvolvimento.

O Brasil apresentava uma economia industrial sofisticada que, somada à qualidade de sua pesquisa agrícola e à disponibilidade de terras agricultáveis, criavam uma enorme probabilidade de transformá-lo num importante exportador - e, portanto importador de bens de capital e tecnologia - principalmente depois da flutuação cambial efetivada em 1999. A Rússia, depois do desastre político, da tumultuada apropriação de seu estoque de capital e recursos naturais por membros do antigo regime, desenvolveu rapidamente sua produção de energia em meio a uma crise política aguda. A Índia transformou-se num importante centro de produção de serviços essenciais à economicidade exigida pela feroz competição gerada pela globalização sem resolver seu problema religioso. A China, desde a corajosa e inteligente reforma de Deng Xiaoping (1979), alterou em $180^{\circ}$ a orientação política da economia e transformou-se numa espantosa "base exportadora" para as empresas americanas e japonesas (associadas às chinesas). Entrou no século XXI cumprindo largamente, por antecipação, a profecia, mas não encontrou o caminho da liberdade política.

O Brasil tinha (e tem) uma vantagem sobre aqueles países: resolveu de maneira satisfatória o "acerto de contas" com o passado. Foi a passagem de uma sociedade autoritária para uma sociedade democrática, conservando a sua integridade territorial e aprofundando a sua unidade. É hoje uma república democrática com sólidos alicerces institucionais. Rússia e China têm ainda de fazer essa transição e a Índia tem que acomodar as diferenças religiosas dentro de si mesmas e com o vizinho Paquistão. Para o analista que prospecta o futuro, esses

*Professor Emérito da FEA-USP e ex-ministro da Fazenda. Endereço eletrônico: dep.delfimnetto@camara.gov.br. 
problemas são sempre uma interrogação importante, pois uma transição tumultuada pode significar um grande desarranjo econômico.

Infelizmente, a vantagem inicial de nada nos serviu: nos últimos cinco anos (três de FHC e dois de Lula) atrasamo-nos de forma lamentável, como se vê na tabela abaixo:

Tabela 1. Crescimento e Inflação dos BRICs - 2000-2005(média anual \%)

\begin{tabular}{lcc}
\hline & Crescimento & Inflação \\
\hline Brasil & 2,6 & 8,6 \\
Rússia & 6,8 & 16,5 \\
Índia & 5,7 & 3,9 \\
China & 8,5 & 1,1 \\
\hline
\end{tabular}

Fonte: FMI.

Deveria ser evidente que, a despeito da melhora da situação econômica dos últimos três anos, promovida basicamente pela expansão das exportações, há qualquer coisa muito errada no "mix" de política econômica. O uso abusivo da política monetária em condições adversas e a absurda "crença" do Banco Central de que o Brasil não pode crescer mais do que $3,5 \%$ ao ano transformou o Real na moeda mais valorizada do Mundo e estão pondo em risco mesmo as pífias melhorias obtidas até aqui.

\section{II}

Os últimos 10 anos da economia brasileira foram um verdadeiro pesadelo: o crescimento per capita do PIB foi de apenas $0,8 \%$ ao ano, nesse ritmo ele dobrará apenas a cada 88 anos! O programa de combate à inflação foi inicialmente brilhante, para depois se arrastar num processo aleatório, mantendo a taxa de inflação flutuando em torno de $7,2 \%$ entre 1999 e 2004. A política cambial, controlada pelas maiores taxas de juros reais do mundo entre 1995-1998, quando o Brasil "quebrou" e teve de ir ao FMI, só melhorou depois que o mercado impôs a desvalorização de 1999. Mesmo assim, tivemos de voltar ao FMI em 2002 depois de acumular o déficit em conta-corrente da ordem de 186 bilhões de dólares e de vender apressadamente parte do patrimônio nacional, que os privilegiadíssimos "fundos de pensão" das Estatais e o BNDES parecem querer agora reestatizar.

6 
Terminamos o ano de 2002 (dez anos após a tentativa de estabilização) com indicadores macroeconômicos pavorosos:

1

2.

3

4.

5.

6.

7.

Para compreender a gravidade da situação é preciso lembrar que o Mundo considera "virtuoso" o país em que a Dívida Líquida/PIB é da ordem de 30\%; em que a relação Dívida Externa Líquida/Exportação é da ordem de 1,5 e cuja relação Amortização + Juros/Exportação é da ordem de 30\%. Todos os nossos indicadores em 2002 eram o dobro do que geralmente se considera a "normalidade".

A despeito de todo o esforço do Governo e da aparente sofisticação da política econômica, o País atrasou-se dramaticamente com relação aos seus parceiros internacionais que souberam resolver seus problemas de crise, de inflação e de crescimento de forma muito mais eficiente. A maioria deles tem hoje inflação menor do que a nossa e está crescendo, em média, o dobro da nossa velocidade. O imaginoso Plano Real reduziu a inflação de forma brilhante, mas deixou uma armadilha da qual até agora não nos desvencilhamos.

Infelizmente, ao longo da octaetéride fernandista, não se fez um esforço fiscal sério (ainda que essa fosse a promessa original). Apenas no segundo mandato, por exigência do FMI, foram produzidos alguns superávits primários. Se FHC, com sua competência e inteligência, tivesse gasto 10\% do tempo que perdeu (ou ganhou?) na "invenção" da reeleição (péssima idéia num país onde não existe controle social), no reequilíbrio das contas públicas e num verdadeiro "choque de gestão" na obsoleta e acomodada máquina administrativa, a situação seria bem outra. A leniência fiscal levou a uma carga tributária bruta de $38 \%$ do PIB e uma Dívida Líquida do Setor Público/PIB de 56\%, mostrando claramente que o Estado não cabe no PIB brasileiro!

A substituição de governo foi politicamente tranqüila, apesar da inflação anualizada ter voltado a 30\% nos últimos meses de FHC. Isso levou Lula a radicalizar a política monetária no primeiro mês de seu governo elevando a taxa Selic para 26,3\%. O ministro Palocci veio em

Boletim de Conjuntura Economia \& Tecnologia, Ano 01 - Vol. 02 - Julho/ Agosto de 2005 
seu socorro com a política fiscal, elevando o "superávit primário" para 4,25\% do PIB e a inflação recuou rapidamente para o mesmo nível anterior, isto é, em torno de 7,2\% ano.

Nos dois anos e meio do Governo Lula a situação melhorou (graças aos efeitos da desvalorização cambial de 1999), mas a armadilha não foi superada no que diz respeito ao crescimento e à inflação, como se vê abaixo:

Tabela 2. Taxa de crescimento do PIB e taxa de inflação - 1996-2005

\begin{tabular}{lcc}
\hline Período de governo & \multicolumn{2}{c}{ Taxas médias anuais } \\
\cline { 2 - 3 } & PIB & Inflação \\
\hline $1996-2002^{*}$ & $2,10 \%$ & $7,40 \%$ \\
$2003-2005$ (até junho) & $2,80 \%$ & $8,00 \%$
\end{tabular}

Fonte: Banco Central do Brasil. * Sem o ano de 1995 devido a inflação residual de 22,4\%.

Mas os indicadores externos da economia melhoraram:

Tabela 3. Indicadores externos

\begin{tabular}{lcc}
\hline & $\mathrm{dez} / 02$ & maio/05 \\
\hline 1. Dívida Líquida/ Exportações & $55,50 \%$ & $50,30 \%$ \\
2. Dívida Externa/Exportações & 3 & 1,5 \\
3. Amortização+Juros/Exportações & $71,40 \%$ & $44,10 \%$ \\
\hline
\end{tabular}

Fonte: Banco Central do Brasil.

A "melhoria" se deve, basicamente, ao aumento das exportações estimulado pela taxa de câmbio, que agora sofre com a absurda política de juros. Esses fatos confirmam que o "mix" atual da política econômica não nos oferece qualquer saída. Ou enfrentamos de vez a necessidade de acomodar o Estado Brasileiro dentro do PIB com um profundo choque de gestão que lhe dê eficiência e com uma nova política fiscal de equilíbrio nos próximos quatro ou cinco anos, ou vamos continuar patinar indefinidamente na mesma mediocridade dos últimos 10 anos...

\section{III}

A sugestão - despojada de qualquer originalidade - de, em vez de continuar trabalhando com o conceito de "superávit primário", escolhido a cada ano, deveríamos trabalhar com "superávits progressivos" que, no horizonte de quatro ou cinco anos, produzam um déficit nominal zero, anteciparia uma forte redução na estrutura a termo nas 
taxas de juros e reduziria fortemente a relação Dívida Líquida/PIB, como sugerem muitos trabalhos empíricos. Sua execução exige um projeto de emenda constitucional (PEC) que: $1^{\circ}$ ) coloque os objetivos do programa nas disposições transitórias e $2^{\circ}$ ) dê ao Executivo uma ampla liberdade de se auto-organizar para produzir um "choque de gestão" capaz de aumentar sua produtividade. Quando a queda da relação Dívida/PIB tiver antecipado a volta da taxa de juro real para níveis civilizados (provavelmente no ano do "equilíbrio") pode-se voltar ao processo de produzir "superávits primários" para estabilizá-la ou continuar a reduzi-la. O ano da obrigatoriedade do "equilíbrio" é único: ele define o sucesso ou o fracasso do programa. O dispositivo da disposição constitucional transitória morre com ele!

A sugestão parece factível neste momento porque:

1. graças ao trabalho inteligente da Secretaria do Tesouro, o montante da dívida interna em dólares referenciada em Reais chegou a 4\% do total e poderá ser eliminada. A dívida externa líquida do setor público é cada vez menor. Logo a dependência da Dívida/PIB com relação às flutuações da taxa de câmbio será cada vez menor;

2. diante da armadilha da política econômica atual, o Governo parece disposto a um programa de controle das despesas relativamente longo (como se vê no projeto de LDO enviado ao Congresso) e decidido a estimular a redução paulatina de parte das vinculações orçamentárias. É evidente que o Estado brasileiro precisa ser submetido a um "choque de gestão" capaz de transformar sua gordura em musculatura, o que recomendaria um aprofundamento das privatizações. O desperdício, a falta de foco dos programas e o excesso de vinculações são as causas da ineficiência geral e que geram as oportunidades para a corrupção, como é cada vez mais visível;

3. o objetivo de déficit nominal zero num horizonte bem definido, com o congelamento das despesas de custeio em lugar do aumento de impostos, criará instantaneamente uma expectativa de baixa do juro real, que facilitará à Secretaria do Tesouro a substituição de parte da dívida "selicada" para papéis pré-fixados (com prazos maiores), aumentando a potência da política monetária. Com isso caminharemos com relativa rapidez para taxas de juros reais civilizadas, reduzindo dramaticamente os gastos com juros e facilitando as manobras de um banco central autônomo. A idéia de que isso atrapalhará a política monetária desconhece esta dinâmica.

4. a redução do juro real e uma redução das tarifas alfandegárias estimulará uma elevação da taxa cambial. Isso despertará o "espírito animal” dos empresários, levando a um aumento do nível dos investimentos que acelerará o crescimento do PIB sem nenhuma 
pressão inflacionária. Isso, acompanhado por um aumento da política de competição e de uma abertura séria ao investimento direto estrangeiro através de zonas de processamento de exportação, produzirá a aceleração do crescimento, que com as despesas de custeio fixadas em termos reais levará à redução natural da carga tributária bruta.

É inteiramente óbvio que o sucesso do programa depende da credibilidade que ele despertar. Esta, por sua vez, depende que ele seja estabelecido na forma de uma emenda constitucional como disposição transitória. Estranha-se tal radicalização, mas a verdade é que depois de dez anos de "nhem nhem nhem" ninguém acredita mais em promessa de superávit primário. Os primeiros quatro anos de FHC foram de absoluta irresponsabilidade fiscal e o controle da inflação coube ao câmbio sustentado pela maior taxa de juro real do Mundo. No segundo mandato (depois de termos sido salvos do default pelo FMI) realizou a promessa de um superávit primário anual de 3,5\%, mas terminou com uma relação Dívida Líquida/PIB de $56 \%$ !

O Governo Lula aumentou o superávit e em maio de 2005 a Dívida Líquida/PIB andava em torno de 50\%. Não há nenhuma garantia de que caminhemos para uma redução mais rápida dessa relação. Uma prova concreta é a emenda aprovada pelo Congresso para estabelecer um tipo de superávit primário “anticíclico" (que esperamos seja vetada). A idéia é sofisticada, mas absolutamente inapropriada para o momento atual em que temos de dar sinais claros de que é o equilíbrio fiscal que vai levar o mercado a reduzir a taxa de juro real.

A radicalização é necessária porque dez anos depois do Plano Real, que tinha como seu alicerce de longo prazo o equilíbrio duradouro das contas públicas, continuamos a patinar no mesmo problema. Não é à toa que os agentes não confiam em meras promessas do Executivo.

O programa é difícil e exige sacrifícios? Claro que sim! Mas é absolutamente necessário (este ou alguma coisa equivalente) para devolver a crença de que voltaremos a crescer com estabilidade interna e externa.

\section{IV}

Há algumas objeções que precisam ser analisadas. A primeira é que seria melhor continuarmos a observar a dinâmica da dívida. É exatamente o que temos feito a oito anos, patinando em torno dos mesmos números! Cálculos abstratos que prevêem uma redução bem sucedida da relação Dívida/PIB têm sido um esporte nacional mal sucedido. O objetivo de déficit nominal zero, num determinado ano, será construído no tempo pelo congelamento 
real do custeio e pelo ganho da produtividade da máquina pública. Em quatro ou cinco anos melhoraremos a qualidade dos serviços públicos, particularmente saúde, educação e a previdência social, enquanto se reduzirá mais rapidamente a relação Dívida/PIB, levando ao longo do tempo a taxa de juro real para nível civilizado. A taxa de juro real "natural" de equilíbrio no Brasil não deve ser maior do que $3 \%$ ou $4 \%$ ao ano.

A segunda objeção é que o déficit nominal zero poderia inibir a ação do Banco Central autônomo, pois evidenciaria claramente o custo da política monetária. Isso talvez pudesse acontecer com o nível de taxas de juros reais que povoam as mentes e controlam os corações de um número excessivamente grande de alguns de nossos competentes economistas: para eles qualquer taxa de juro real abaixo de $8 \%$ é um pecado contra o “capital”! Com as condições expostas acima, entretanto, as manobras de juro real seriam muito menores porque a potência da política monetária seria maior, mas eventualmente, teriam mesmo de ser acompanhadas pelo corte das despesas, o que apenas explicitará o seu custo. Fica evidente que o "truque" do superávit primário escamoteia parte desse custo que aparece como um resíduo: o déficit nominal!

A terceira objeção é, politicamente, a mais difícil de ser enfrentada, refere-se às vinculações, que os experts têm confundido como corte das despesas. As poderosas corporações da "saúde" e da "educação" têm razão quando defendem a importância desses setores para o bem-estar da sociedade. A educação é, obviamente, quem constrói o próprio homem. Ela é o instrumento pelo qual ele explicita cada vez mais sua humanidade. A saúde lhe permite viver essa humanidade mais prazerosamente. Não se trata de discutir, portanto, a altíssima prioridade dos gastos públicos nos dois setores. $O$ que se trata é discutir se o método mais eficiente de produzir mais e melhor educação e saúde é o mecanismo das "vinculações".

Há séria controvérsia. Com a vinculação, a análise dos processos eficientes fica muito prejudicada: a tendência natural dos homens é a acomodação a um padrão de esforço "confortável". Isso significa que métodos e processos tendem a perpetuar-se e a produzir a esclerose que é visível (com raríssimas exceções) nos serviços públicos.

Qualquer "vinculação" deveria ser acompanhada pela exigência de um aumento mínimo de produtividade anual, objetivamente mensurável. Tais setores deveriam ser objetos de rigorosa vigilância e um poderoso choque de gestão acompanhado por um orçamento de base zero. Na forma atual, as "vinculações" são a mãe do desperdício, da acomodação e da perpetuação da ineficiência. É um grave erro pensar que reduzir as vinculações é reduzir a 
quantidade e a qualidade dos serviços de educação e saúde. Os ganhos de produtividade e a economia de juros que se fará provavelmente aumentarão, e muito, a oferta pública desses dois serviços essenciais para o bem estar da sociedade brasileira.

É importante chamar a atenção para o seguinte: o déficit nominal zero a ser atingido em quatro ou cinco anos é apenas o indicador que, realizado, consagraria o sucesso do programa. O programa mesmo é o aumento do superávit primário com o congelamento real dos gastos de custeio do governo acompanhado por uma licença de realizar o "choque de gestão" que aumentará a produtividade do Estado. É isto que permitirá um volume maior e uma maior qualidade dos serviços prestados à população. O que se poupará com os juros e com o excedente vindo do aumento da produtividade serão destinados aos investimentos públicos - inclusive em educação e saúde - que potencializa os efeitos dos investimentos privados. Haverá uma aceleração do desenvolvimento, ao contrário do que supõem alguns nefelibatas keynesianos de última hora... 